\title{
Analysis of Multicast Routing Protocol for Ad Hoc Mobile Wireless Networks
}

\author{
Sandeep kaur \\ Dept of computer science \\ Lovely professional university
}

\author{
Navjotpal kaur \\ Dept of computer science \\ lovely professional university
}

\begin{abstract}
Mobile ad-hoc networks (MANETs) allow portable mobile devices to establish communication path without having any central infrastructure. In the multicast routing protocol the source based tree and core based tree used for the multicast routing they both are help in the AODV and DVMRP. In this paper we describe the various types of the source and core based tree for the multicast routing protocol. In this paper we give the comparisons and the operations which they both are perform. We also describe the various characteristics of the AODV and the DVMRP.
\end{abstract}

\section{General Terms}

AODV (Ad hoc on demand distance vector), DVMRP (Distance vector multicast routing protocol), CBT (core base d tree), SBT (source based tree)

\section{Keywords}

Mobile ad hoc networks, operations, tree, protocol, networks Multicast mesh, scalability.

\section{INTRODUCTION}

By multicast routing protocol we mean to describe structure and operation of the multicast routing protocols. Structure defines the data types, comparisons and its characteristics. Multicast is the transmission of packets to a group of zero or more hosts identified by a single destination address [2]. The existing ad hoc routing protocols are DVMRP, AODV, CAMP, ODMRP, and LBM. In this paper firstly examines routing protocol designed for the ad hoc networks and their various characteristics and comparisons of the different routing protocols. Distance vector multicast routing protocol initially designed for the wired network and the AODV supports the initially unicast and subsequently covers the multicast routing. Core Assisted Mesh protocol is based on the each multicast group and ODMRP is a flooding based multicast routing protocol. The local based multicast uses location information to distribute multicast traffic to the destination multicast group, which is also defined as all nodes residing in a specific geographical region called a multicast region. This document describes the Ad hoc Multicast Routing Protocol (AM Route), which enables the use of IP Multicast in MANETs. Existing multicast protocols ([4], [5], [6]) do not work well in MANETs as the frequent tree reorganization can cause excessive signaling overhead and frequent loss of datagram's. MANETs deliver lower bandwidth than wired networks; therefore, the information collection during the formation of a routing table is expensive

\section{PERFORMANCE OF EXISTING AD HOC ROUTING PROTOCOLS}

Multicast routing protocol for mobile networks generally categorized as source- based tree, Core based tree, Location based tree, and Stability based tree, Multicast mesh and Group based forwarding. Source

\subsection{Source based Multicast Tree}

A multicast tree is established and maintained for each multicast source node in each multicast group. Thus, in an environment with $\mathrm{G}$ multicast groups where each group has $\mathrm{S}$ multicast source nodes, there will be $(\mathrm{G} * \mathrm{~S})$ multicast trees established and maintained. The advantage is that each multicast packet is forwarded along the most efficient path from the source node to each and every multicast group member. A multicast tree can be established based on various objectives. The Minimum Steiner Tree (MST) minimizes total cost. This is desirable in many situations, but the exact algorithm is infeasible (NP-complete). Shortest Path Trees (SPTs) minimize the cost between the source node and each multicast member individually. This is simpler and more widely used. Overall, the SBT scheme suffers from scalability problems because a lot of overhead is incurred in establishing and maintaining several multicast trees as the number of multicast groups and multicast source nodes increases. Also, it may require prior knowledge of topology information. In a mobile ad hoc network, frequent topological changes become another significant factor in increasing the overall overhead since many source-based trees will be affected and will need to be repaired. Examples of SBT protocols are DVMRP.

\subsection{Core Based Tree}

CBT is a more scalable approach than the SBT approach. Instead of building multiple trees for each multicast group, a single shared tree is used to connect all multicast group members. Multicast packets are distributed along this shared tree to all members of the multicast group. To establish the shared tree, a special node is designated as the core node, which is responsible for creating and maintaining the shared tree. Hence, a core selection algorithm is needed. The established shared tree can be either unidirectional or bidirectional. In a unidirectional shared tree, multicast packets must be unicast to the core node, which is the root of the tree. From the core node, the multicast packets will be distributed along the shared tree until they reach all the multicast group members. However, in a bidirectional shared tree, multicast packets can enter the shared tree at any point and they will be distributed along all branches of the shared tree. Obviously, the bidirectional scheme is more efficient in term of both communication performance and forwarding overhead forwarding overhead is defined as the number of transmissions needed to forward the multicast packet towards the destination. One disadvantage of the CBT approach is that 
traffic is concentrated on the shared links, which results in a high tendency for congestion at the shared links. In addition, the multicast packets tend to be forwarded along less optimal paths since they are forced to transit along the shared tree. Moreover, the core node, which is the most critical component in this scheme, becomes the single point of failure. A robust and efficient CBT protocol usually provides mechanisms to dynamically adapt the shared tree into a more efficient configuration and to recover from the core node problem. The routing protocol utilized for the scalability study is the Ad hoc On-Demand Distance Vector (AODV) protocol [8],[9].These extra mechanisms incur additional overhead. Examples of CBT protocols are CBT, AODV. Most of the existing schemes (AODV) depend on individual receivers to detect congestion and adjust their receiving rates which are much disadvantageous[7].

\subsection{Distance vector multicast routing protocol 2.1}

(DVMRP) is a multicast routing protocol initially designed for wired networks. The extensions were presented to allow DVMRP to function more efficiently in mobile ad hoc networks. the distance -vector based mechanism to provide shortest part information to the multicast source nodes . This information is used reverse path forwarding algorithm routes to the source node can change faster than the routing protocol can keep track. In RPF algorithm fails to operate efficiently. In instead of RPF, checking for packet duplication is used and ensuring each node rebroadcast only non- duplicate packets.

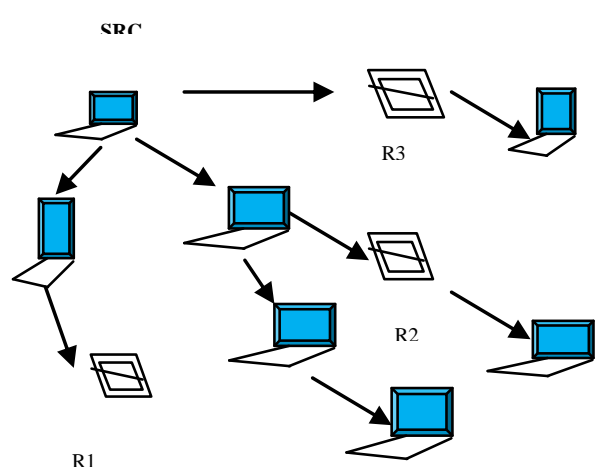

(a) A multicast packet is flooding to all nodes a tree rooted at the source node can he deriver
Dynamic grafting/pruning is another extension helps in speeding up multicast tree reconfirmation when DVMRP is used in mobile ad hoc network

The broadcast and prune process is completed in the figure 1 . The join / leave operation is controlled by the whether or not the prune message is propagated upstream. Periodically the timer on the pruned branch will expire and the multicast traffic will be flooded again if there are still no member in the branch the prune message will be sent otherwise no prune message is sent and the branch will not be pruned off. This mechanism incurs latency when new members wish to join the group since a new member has to wait until the next flooding period, a new message can explicitly send graft message upstream to connect the previously pruned- off branch to the multicast tree. One problem arises when using DVMRP in a mobile ad hoc network. According to DVMRP, the prune message will be initiated at the non-member leaf node and propagated upstream.

However, in a mobile ad hoc network, it is difficult for a node to determine whether it is the leaf node or not. Two schemes are possible to resolve this problem. One is to use acknowledgment messages and the other is to exchange routing tables among neighbors.

With these methods, a node can easily determine if it is the leaf node of the multicast tree or not and be able to initiate the prune message properly. Due to its ease of deployment and no centralized control unit, mobile nodes can connect with each other in any form of network topology anytime [2][3].

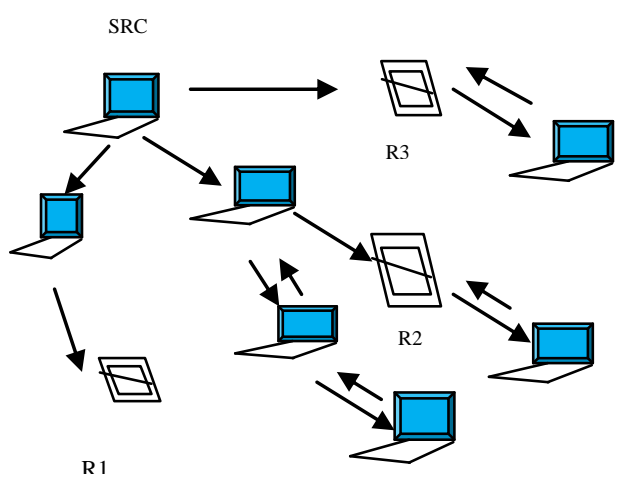

(b) Leaf nodes are identified prune messages are sent if multicast data are not desired on the designated link
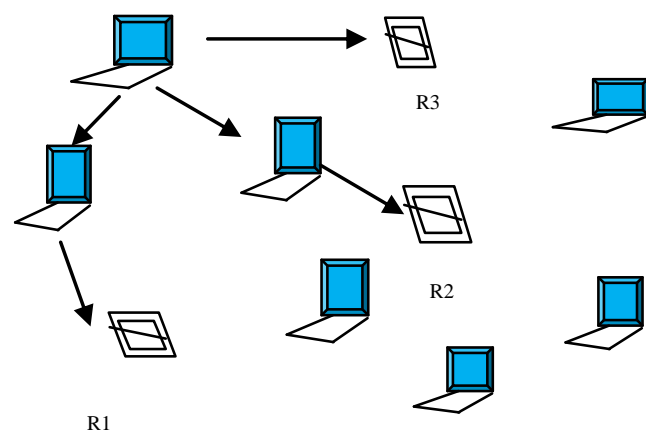

(c) The source- based multicast tree 


\subsection{Ad hoc on demand distance vector AODV 2.2}

Multicast creates and maintains a single shared tree per multicast group. Each multicast group has a group sequence number. This group sequence number is periodically incremented and broadcast throughout the network by the multicast group leader. The first node requesting a route to a particular multicast group automatically becomes the leader of that multicast group. Thereafter, the multicast tree is dynamically built as subsequent nodes join the group. A new member node will select the best on-tree node to graft to. This selection is based on the freshness of the group sequence number and the hop distance to another group member.

A leaf node can quit a multicast group by sending a prune message to its next hop on the multicast tree. The next-hop node, on receiving the prune message, will remove the corresponding entry from its multicast route table. If the nexthop node becomes a leaf node as the result of this removal and it downstream nodes. In the latter case, it may be able to prune itself off if it has only one downstream node.

In AODV will randomly nominate themselves as the new multicast group leader when the periodic announcement from the current multicast group leader is not received for a timeout period. Contention mechanism based on node ID is used to resolve the case when several nodes become multicast group leaders of the same multicast group which is possible when the network is partitioned and merged. DVMRP uses the distance-vector routing algorithm, which is a table-driven algorithm, for reverse path forwarding calculation. Ondemand routing is used in AODV
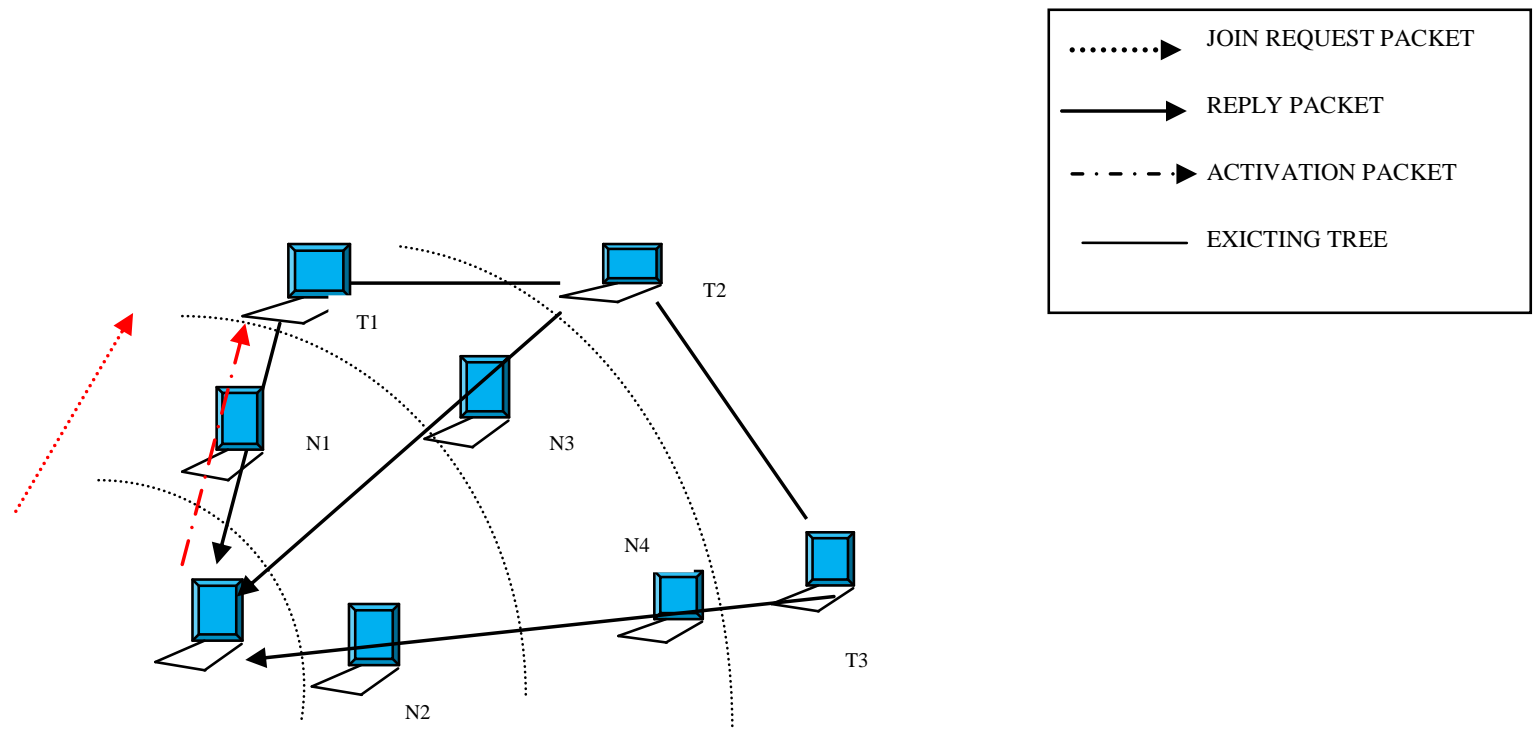

\section{CHARACTERISTICS OF VARIOUS MULTICAST ROUTING PROTOCOLS}

Shows the important characteristics of each multicast routing protocols DVMRP uses the source based tree structure. AODV can be classified as cored- based tree protocol although the term core is not used In AODV terminology this is because normally the first node that request to join the multicast group performs the function of the core node by represented the starting point for the multicast group performs the functions of the core node by representing the starting point for the shared tree establishment in addition to generating the group is not interested in multicast traffic from this group, it can further prune itself from the tree using the same method. When a multicast tree link is broken, the downstream node will initiate the join process as described above. The join request also contains the distance from the multicast group leader so that only the node closest to the group leader can reply If no replies are received, a network partition is assumed and the joining node will designate itself as a new multicast group leader if it is a member of the group; otherwise, the decision will be passed down to one of its
Table 1. Characteristics of Various Ad Hoc Mobile Multicast Routing Protocols

\begin{tabular}{|l|l|l|}
\hline Parameters & DVMRP & AODV \\
\hline $\begin{array}{l}\text { Multicast Delivery } \\
\text { Structure }\end{array}$ & Source-Based Tree & Core-based Tree \\
\hline $\begin{array}{l}\text { Use Centralized } \\
\text { Node }\end{array}$ & No & $\begin{array}{l}\text { Yes (Multicast Group } \\
\text { Leader) }\end{array}$ \\
\hline $\begin{array}{l}\text { Core Node } \\
\text { Recovery }\end{array}$ & N/A & On-demand \\
\hline $\begin{array}{l}\text { Routing Scheme } \\
\text { Dependence on Nable-driven } \\
\text { Unicast Routing } \\
\text { Protocol No }\end{array}$ & No \\
\hline
\end{tabular}




\section{OPERATION AND PERFORMANCE DIFFERENCES}

Session refer to the communication from a specific multicast source node to a specific multicast group. In this case, there can be several multicast sessions for each multicast group depending on the number of multicast source nodes in that multicast group.

DVMRP times out the pruned-off branches periodically. The net effect can be compared to periodic flooding of multicast data. In AODV, only the multicast group leaders periodically flood the updated sequence number.

Multiple routes ODMRP can exploit the presence of multiple routes. The advantage is that there is no disruption to ongoing traffic when the primary route is broken. However, these protocols result in unnecessary packet forwarding unlike DVMRP and AODV, which provide only a single route for each multicast session.

Table2. Comparisons of Overhead in Ad Hoc Mobile Multicast Routing Protocols

\begin{tabular}{|l|l|l|}
\hline Parameters & DVMRP & AODV \\
\hline $\begin{array}{l}\text { Information } \\
\text { stored at each } \\
\text { node }\end{array}$ & $\begin{array}{l}\text { Prune status of all } \\
\text { adjacent link }\end{array}$ & $\begin{array}{l}\text { On-tree nodes } \\
\text { record all its } \\
\text { upstream link and } \\
\text { downstream link }\end{array}$ \\
\hline $\begin{array}{l}\text { Amount of } \\
\text { information at } \\
\text { each node in }\end{array}$ & $\begin{array}{l}\text { One set for each } \\
\text { source node in } \\
\text { each group }\end{array}$ & One set per group \\
\hline $\begin{array}{l}\text { Scalability in } \\
\text { terms of storage } \\
\text { overhead in }\end{array}$ & poor & good \\
\hline $\begin{array}{l}\text { Scalability } \\
\text { terms of overall } \\
\text { communication } \\
\text { overhead }\end{array}$ & & \\
\hline
\end{tabular}

\section{CONCLUSION}

Ad hoc wireless multicasting is a challenging communication feature that requires new protocols to support it. Most multicast routing protocols designed for the Internet assume that routers in the network are static and they have no provision to deal with tree fragmentation and repair over time when mobility occurs. Some proposals are plain extensions of distance-vector and link-state routing protocols. Such proposals, however, do not perform well in ad hoc mobile networks due to the presence of mobile links at each portion of the route. In addition, multicasting is complicated by the presence of multicast group dynamics. However, multicasting is essential if multiparty communications and multiparty multimedia-based applications are envisioned for wireless ad hoc networks.

\section{ACKNOWLEDGMENTS}

I am thankful to my dear friends Lovely Professional University for her timely advice and support in carrying out my work

\section{REFERENCES}

[1] Ballardie, T., ICore based Trees (CBT) Multicast Routing Architecture," RFC 2201, Sept. 1997.

[2] C- C. Chiang, M. Gerla and L Zhang," Shared Tree Wireless

[3] C. E Perkins," Adhoc on Demand Distance Vector (AODV) routing"Proceedings of the IEEE 1997

[4] D.P. Agrawal, Q.A. Zeng, Introduction to wireless an mobile systems, Brooks/Cole, 2003.

[5] Deering, S., et al, Protocol Independent MulticastSparse Mode (PIM-SM): Motivation and Architecture," Internet Draft, draft-ietf-idmr-pim-arch-04, Oct. 1996.

[6] Pusateri, T., Distance Vector Multicast Routing Protocol," Internet Draft, draft-ietf-idmr-dvmrp-v3-06, Mar. 1998.

[7] K.SrinivasaRao et al "Development of Energy Efficient and Reliable Congestion Control Protocol for Multicasting in Mobile Adhoc Networks compare with AODV Based on Receivers". Vol. 2, Issue 2,Mar-Apr 2012, pp.631-634.

[8] S. Basagni, I. Chlamtac, V.R. Syrotiuk, and B.A. Woodward, \A Distance Routing Effect Algorithm for Mobility (DREAM),"Proceedings of the ACM/IEEE International Conference on Mobile Computing and Networking (MOBICOM), Dallas, TX, October 1998,pp. 76-84

[9] R.E. Bellman, Dynamic Programming, Princeton University Press, Prince- ton, NJ, 1957 